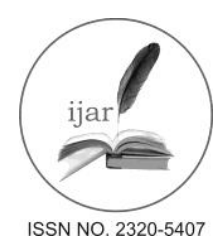

Journal homepage:http://www.journalijar.com INTERNATIONAL JOURNAL

Journal DOI: $\underline{10.21474 / I J A R 01}$

OF ADVANCED RESEARCH

RESEARCH ARTICLE

\title{
PREPARATION OF (PHTHALCYANINATO) BIS (4-METHYLPYRTDTNE) IRON(II) AND STUDY OF IT'SSPECTROSCOPIC AND STRUCTURAL PROPERTIES.
}

*HasanSabeehJabur.

Chemistry Department college of science .University of Al-Muthana . Al-Muthana .Iraq.

\section{Manuscript Info Abstract}

\section{Manuscript History:}

Received: 25 April 2016

Final Accepted: 19 May 2016

Published Online: June 2016

Key words:

Bis adduct of phthalocyaninatoiron

,metallopthalocyanine, structural

properties of the

phthalocynainatoiron

*Corresponding Author
Bis adduct of phthalocyaninatoiron (II) with 4-methylpyridine was prepared and characterized. The effect of axially coordinated 4-methylpyridine on the spectroscopic and structural properties were investigated, mainly by UVvisible. IR and fast atom bombardment mass (FAB*) In addition the crystal structure was studied by the X-ray powder diffraction technique.

HasanSabeehJabur.

Copy Right, IJAR, 2016,. All rights reserved.

\section{Introduction:-}

The reaction between some metallopthalocyanineMPc $(\mathrm{M}=\mathrm{Co}, \mathrm{Fe}, \mathrm{Ru}, \ldots)$ with coordinated bases pyridine , pyrazine , tetr:azine and other's gives either mono or bis adduct depending on the metal, temperature, time of reaction, steric and electronic properties of the base ${ }^{(1-4)}$, This paper investigates the effect of the adduct (4-methylpyidine) the spectroscopic- and structural properties of the phthalocynainatoiron (II)

Preparation of o- cyanobenzamide:-

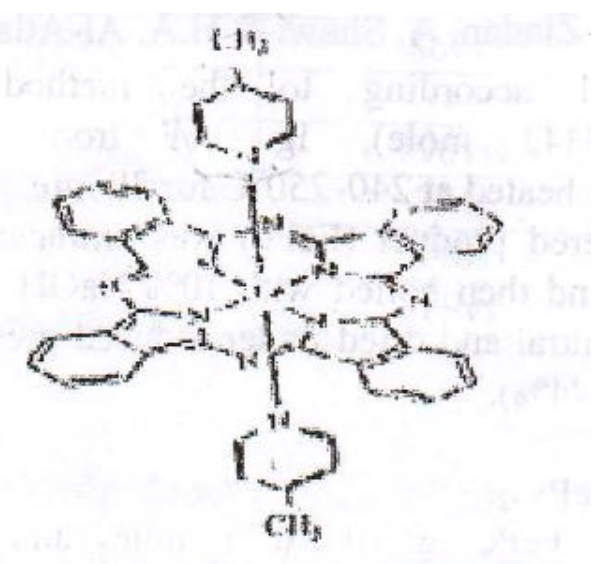

Fig.1 werentem

O-cyanobenzamide was prepared according to the method of Lowery et.al" ${ }^{(5)} 20 \mathrm{~g} .(\mathrm{O} .136 \mathrm{~mol})$ of Phthalimide was stirred with $100 \mathrm{ml}$ (excess) of conc. Ammonium hydroxide (25\%) for 24 hours at room temperature. The produced Phthalimide was then filtrated off washed with water and ethanol, and dried at 100C, (yield 20.75g.,,,93\%). 
A mixture of phthalamidel6g. (0.0975 mole), acetic anhydride $60 \mathrm{ml}$ and $10 \mathrm{ml}$ of acetic acid was refuxed for 45 min. and the resultant solution was filtered and the filtrate allowed to cool to $40 \mathrm{C}$ and then re-foltred.The solid product (ocyanobenzinmide) was washed with acetic acid, water and re-crystallized from ethanol and dried at 110 "C for 24 hours (yield 6.5 g., 45.6\%),m.p. 170-171 C,,lit. 172C ${ }^{(5)}$.

\section{Preparation of FePc:-}

FePc was prepare according to the method of Barrett et.a1. ${ }^{(6)}$ o-cyanobenzamide $5 \mathrm{~g}$ (0.0342 mole), $1 \mathrm{~g}$, of iron filing and $10 \mathrm{~g}$ of naphthalenel. Were heated at $240-250 \mathrm{C}$ for $30 \mathrm{~min}$.

The dark blue powdered product $(\mathrm{FePc})$ was extracted with boiling acetone, filtered (while it is hot), and then boiled with $10 \% \mathrm{NaoH}$, washed with hot water until the filtrate became neutral and dried under reduced pressure ( 0.01 ton) for four hours at 800C. (yield 3,6g.,74\%).

\section{Preparation of PcFe (4-MePy)2:-}

A suspension of FePclg . (0.00176 mole) and 4-methylpyridine 15ml (excess) was heated under reflux for 1 hour, and then filtered while it is hot to remove the uncreated FePc. The solution was allowed to cool and then filtered ' The blue solid product was washed with diethyl ether and dried under reduced pressure $(0,01$ ton) for two hours at 300C (yield 0.939., 7A\%).

\section{Results and Discussion:-}

Uv=Visible : Electronic spectra were recorded on PyeUnicam SP8-100 spectrophotometer. The electronic absorption spectra of $\mathrm{PcFe}(4-\mathrm{MePy})_{2}$ and FePc exhibit some similarities as shown in Table 1. Both compounds show the characteristic $\mathrm{Q}$ and $\mathrm{B}$ bands. The band at $415 \mathrm{~nm}$ in PcFe (4-MePy)z spectra in both $\mathrm{DMF}$ and $\mathrm{Cl}_{2} \mathrm{~B}$ are attributed to metal $\rightarrow$ ligand charge transfer $\mathrm{t}^{(7)}$.

Table (1) The absorption bands of PcFe(4-MePy) 2 and FePc in different solvents

\begin{tabular}{|c|c|c|c|c|c|}
\hline $\begin{array}{c}\text { Compoun } \\
\text { d }\end{array}$ & $\begin{array}{c}\text { Solven } \\
t\end{array}$ & $\begin{array}{c}\text { Q-band } \\
\text { 2Maxnm(loge) }\end{array}$ & $\begin{array}{l}\text { Soret band } \\
\lambda \mathrm{Max} n \text { (loge) }\end{array}$ & $\begin{array}{l}\text { M I CT } \\
\text { גMax } \mathrm{nm}(\text { loge })\end{array}$ & Other bands \\
\hline PcFe(4- & DMF & $658(5.13)$ & $332(4.94)$ & $415(4.66)$ & $596(4.79)$ \\
\hline $\mathrm{MePy})_{2}$ & $\mathrm{Cl}_{2} \mathrm{~B}$ & $654(5.1)$ & $335(4.89)$ & $415(4.38)$ & $595(4.57)$ \\
\hline $\mathrm{PcFe}$ & $\begin{array}{l}\mathrm{DMF} \\
\mathrm{Cl}_{2} \mathrm{~B}^{*} \\
\mathrm{ClN}^{*}\end{array}$ & $\begin{array}{c}661(4.83) \\
656(4.84) \\
658(4.7) \\
\end{array}$ & $\begin{array}{c}324(4.82) \\
330(4.68) \\
-\end{array}$ & $\begin{array}{c}398(4.5) \\
- \\
- \\
\end{array}$ & $\begin{array}{c}600(4.49), 628(4.5 \\
595(3.95) \\
597(4.2), 632(4.2 \\
\end{array}$ \\
\hline
\end{tabular}

$\mathrm{Cl}_{2} \mathrm{~B} *$ Dichlorobenzene $\mathrm{ClN}^{*}$ chloronaphtalene DMF* Dimethylformamide

Infra-Red:- The IR spectra were recorded on shimadzu 470 spectrophotometer. The main different between the spectra of the parent and the adduct complex are the bands which attributed to the 4-methylpyridine moiety where the $\mathrm{CH}_{3}$ groups of the adduct shows the asymmetric and symmetric $\mathrm{C}-\mathrm{H}$ stretching at 2910 and $2840 \mathrm{~cm}^{-1}(8)$. There also some other changes in the other bands of the phthalocyanine complexes(Position and intensity) relative to $\mathrm{FePc}^{(9)}$ as shown Table 2. 


\begin{tabular}{|c|c|c|c|}
\hline FePc & $\mathrm{PcFe}(4-\mathrm{MePy})_{2}$ & $\mathrm{FePc}$ & $\operatorname{PcFe}(4-\mathrm{MePy}) 2$ \\
\hline- & $3054 \mathrm{~m}$ & $1116 \mathrm{vs}$ & $1120 \mathrm{vs}$ \\
\hline- & $2910 \mathrm{~m}$ & $1078 v s$ & 1091vs \\
\hline- & $2840 \mathrm{~m}$ & - & $1068 \mathrm{~m}$ \\
\hline $1603 \mathrm{~m}$ & $1600 \mathrm{~m}$ & - & $1020 \mathrm{w}$ \\
\hline $1574 \mathrm{~m}$ & $1574 \mathrm{~m}$ & 944 & $953 w$ \\
\hline $1555 \mathrm{~m}$ & $1555 \mathrm{~m}$ & $905 \mathrm{~m}$ & $912 \mathrm{~m}$ \\
\hline $1539 \mathrm{~m}$ & $1539 \mathrm{~m}$ & $867 \mathrm{w}$ & $870 w$ \\
\hline $1507 \mathrm{~s}$ & $1501 \mathrm{~s}$ & - & $809 \mathrm{~m}$ \\
\hline $1472 w$ & $1472 \mathrm{~m}$ & $796 \mathrm{vw}$ & $796 s$ \\
\hline $1459 w$ & $1456 \mathrm{~m}$ & $774 \mathrm{~s}$ & $777 \mathrm{~s}$ \\
\hline- & $1436 \mathrm{w}$ & $748 \mathrm{~s}$ & $748 \mathrm{~s}$ \\
\hline $1417 \mathrm{~s}$ & $1417 \mathrm{~s}$ & $729 \mathrm{vs}$ & $732 \mathrm{vs}$ \\
\hline- & $1382 \mathrm{~m}$ & - & $665 \mathrm{~m}$ \\
\hline $1324 \mathrm{vs}$ & $1321 \mathrm{~s}$ & $569 \mathrm{~m}$ & $566 \mathrm{~m}$ \\
\hline $1283 \mathrm{~s}$ & $1283 \mathrm{~s}$ & $505 \mathrm{~m}$ & $521 \mathrm{~m}$ \\
\hline- & $1235 \mathrm{w}$ & - & $486 \mathrm{~m}$ \\
\hline- & $1209 \mathrm{~m}$ & - & $460 \mathrm{~m}$ \\
\hline $1168 s$ & $1164 \mathrm{vs}$ & - & $441 \mathrm{~m}$ \\
\hline Continued & Continued & $422 \mathrm{~m}$ & $422 \mathrm{~m}$ \\
\hline
\end{tabular}

$\mathrm{S}$ : strong m: medium w: weak v: verv

Mass Spectrum:- The $\left(\mathrm{FAB}^{+}\right)$mass spectrum was recorded on Finnigan MAT-711A spectrometer, using o-nitrobenzylalcohole (NBA) as a matrix.

The spectrum (Fig.2) possesses a molecular ion $\mathrm{M}^{+}$at $\mathrm{m} / \mathrm{z} 754$ with relative abundance 2.5 and the peak atm/2661.4 with relative abundance 5.2 which attributed to [M- (4-MePy) ${ }^{+}$. The high relative abundance $89 \mathrm{at} \mathrm{m} / \mathrm{z} 567.9 \mathrm{is}$ attributed to $\left[\mathrm{M}-(4 \mathrm{MePy})_{2}\right]^{+}$, which reflect the high stability of $[\mathrm{PcFe}]^{+}$. The peaks at $306,460,6 ! 3$ arc attributed to the matrix (NBA1t"r'

X-ray powder diffraction:- The patterns were recorded on Philips type PW253(X ray diffractometer (X-ray source $\mathrm{Cu} ; \mathrm{K} \& 1.54 \mathrm{~A})$.

The X-ray powder diffraction patterns for FePc and $\mathrm{PcFe}(4-\mathrm{M} . t y)_{2}$ were shown in Figures 3 and 4 respectively, The presence of the peaks at $12.6 \mathrm{~A} 0$ and $11 \mathrm{~A} 0$ and the complete absence of 3.29A peak in the X-ray pattern for suggests a big interplaner spacing between the phatalocyanine rings due to the presence of 4-methylpyridine groups coordinated to the central metal atom in perpendicular plane to the plane of the phthalocyanine ring 


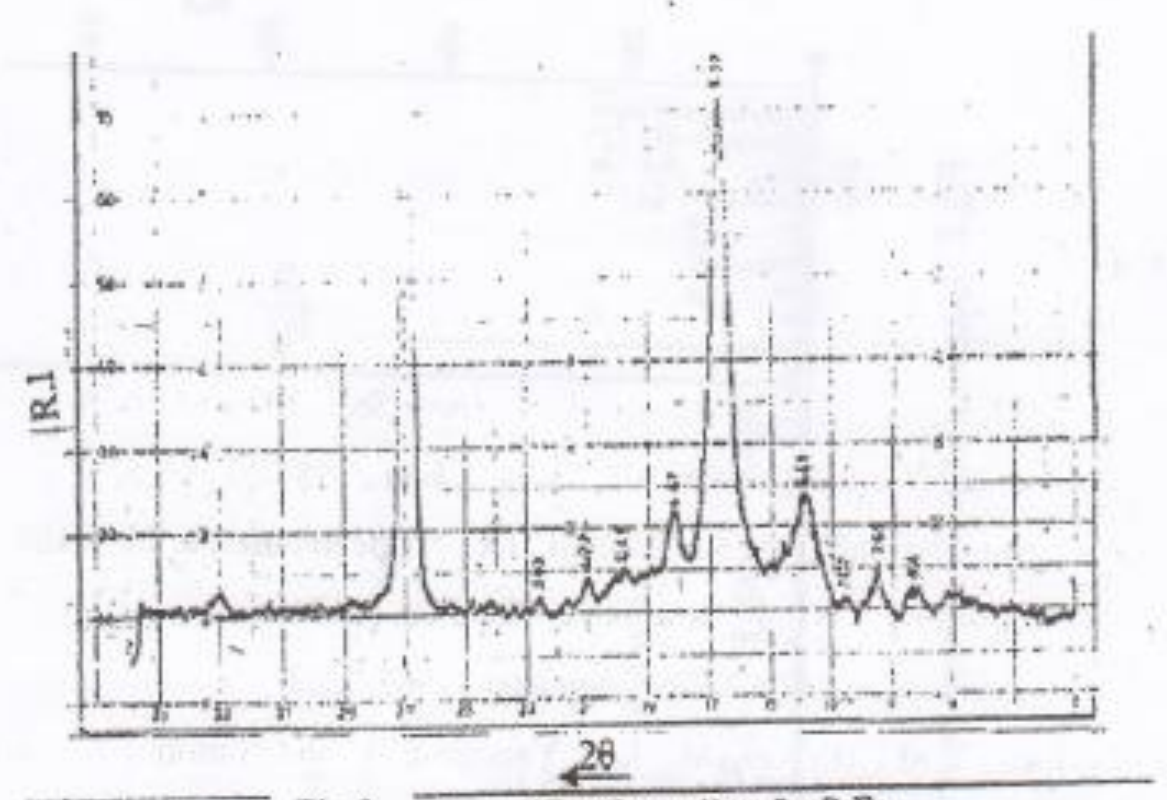

Fig.3 X-ruy dilrruction yatiera For PcFe

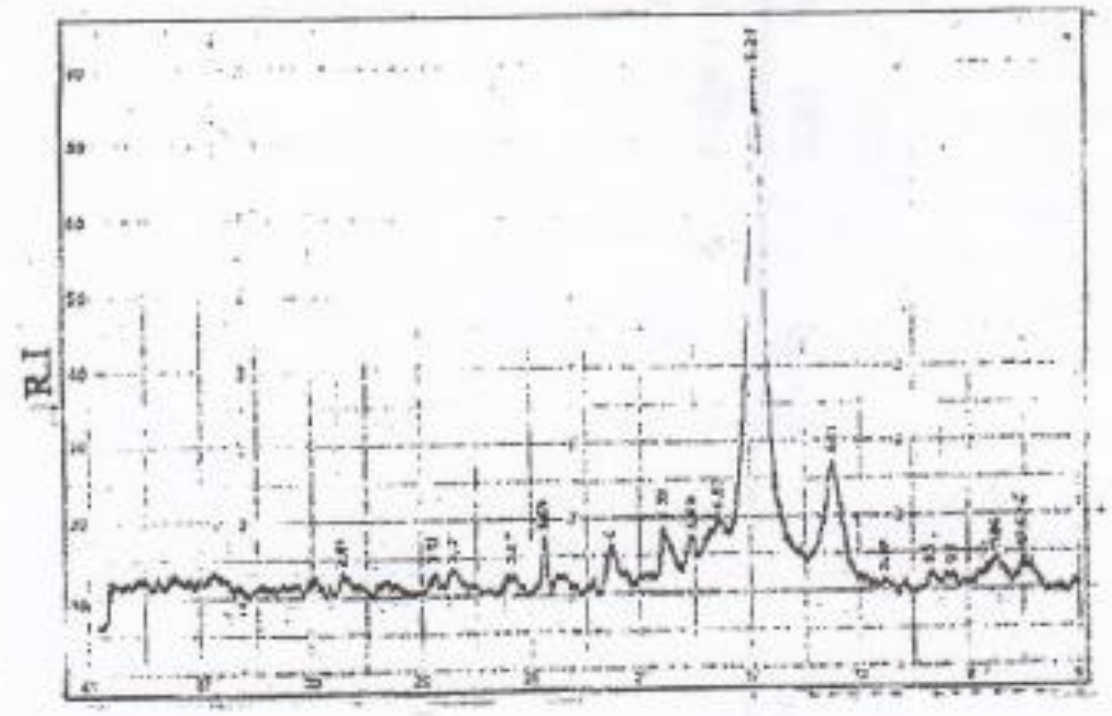

\section{$2 \theta$}

Fig.4 X-ray diffraction pattem for PCFe(4-MePy) 


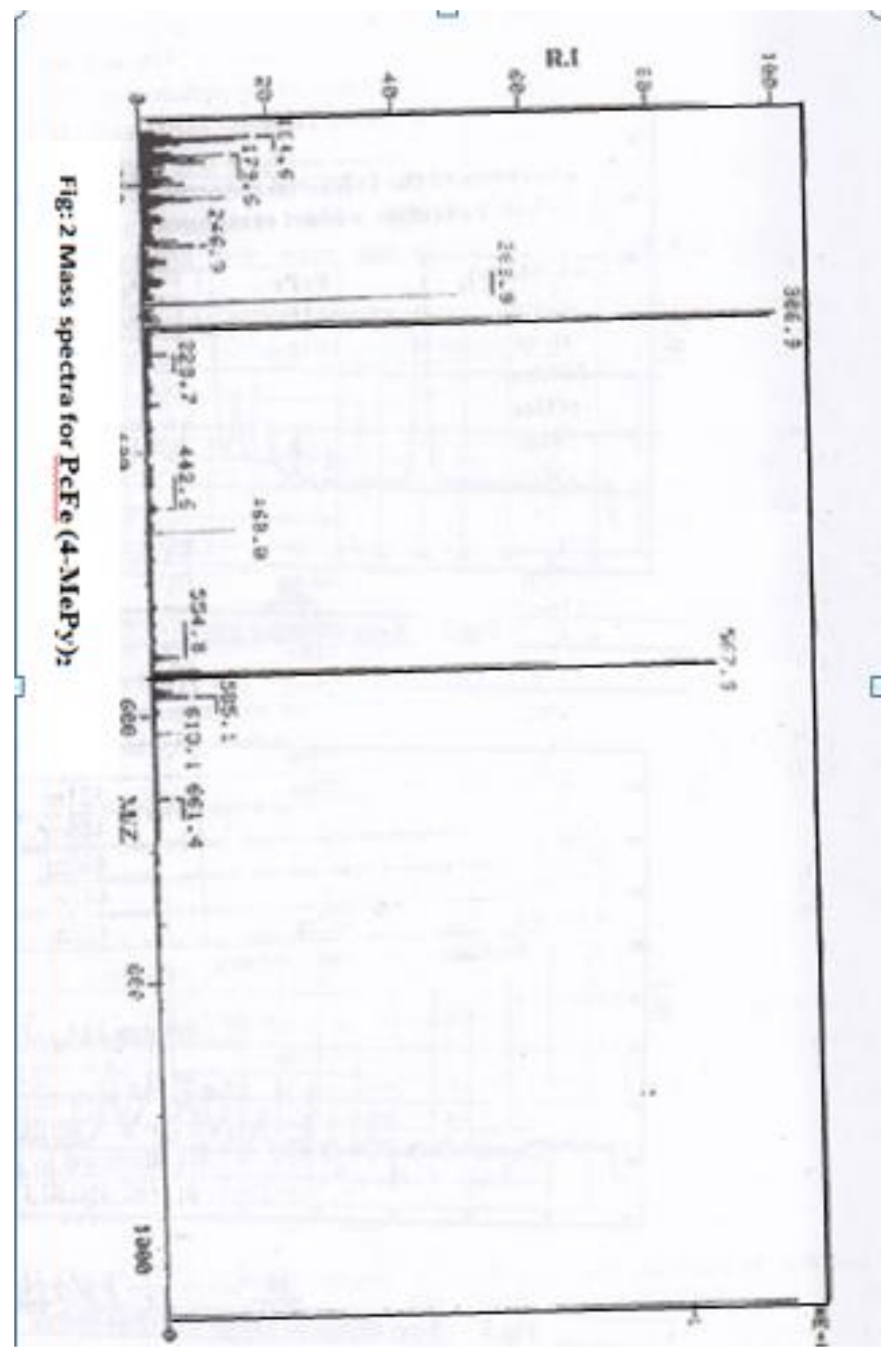

\section{References:-}

1. Hanack,M.;Deger,S'andLange,A;Coord,Chern'Rev"1980,83,115.

2. Cariati,F.:andMicera,G':SpectrochimicaActa.;1980,36A,867.

3. Cariati, F.: and Micera, G.; Zoroadu, M.A and Morazzoni, F' :J.C.S. Datton.535 (1e81).

4. Canari,F.; Morazzoni, F. and Busetto .C.J.C.S., Dalton , 496 (1976).

5. Lowery, M.K; Starshok, A. J. ; John, S.J.; Krueqer. P'C,' and Kenney. M'E: Inorg. Chem., 1965,4,128.

6. Barrett,P.A.;Deirt,C.E.andLinstead,R'P':J'Chem'Soc,1936,1719.

7. Metz,J.;Schneider,O.andHanack,M':Inorg'Chem"1984,23,1065.

8. Silverstein, R.M.; Bassler,G.C.and Morrill, T.C. "spectrometric Identification of Organic Coffi6irnds", Wiley, New York' Third ed' (1974)'

9. Lever A.B.P,: Adv .Inorg.chem.Radio chemistry, 1965'7'27'

10. Nigrimoviskii, V.M.;Bouvel, M.; LukYanets, E.A., and Simon, J.: Journal of porphrins and phthalcyanines, $2000,4,248$. 